\title{
HISTOPATHOLOGY AND BACTERIOLOGY IN HANSEN'S DISEASE
}

\author{
Nila Theresa Davis ${ }^{1}$, Letha $V^{2}$, Sankar $S^{3}$
}

1 Resident, Department of Pathology, Government Medical College, Kottayam.

${ }^{2}$ Additional Professor, Department of Pathology, Government Medical College, Kottayam.

3 Professor and HOD, Department of Pathology, Government Medical College, Kottayam.

\section{BACKGROUND}

ABSTRACT

Leprosy is a disease, which has been associated with tremendous social stigma with cases recorded in the Old Testament. It is an infectious disease caused by Mycobacterium leprae. Leprosy expresses itself in different clinicopathological forms depending on the immune status of the patient. Diagnosis of leprosy only on clinical basis is difficult. So, confirmation of diagnosis in leprosy is an important indication for histopathological examination. The parameters used for the histopathological classification are well defined, precise and also take into account the immunological manifestations which enable it to successfully bridge the pitfalls in leprosy diagnosis. Moreover, correct labelling of paucibacillary and multibacillary cases is a prerequisite to treat them adequately, which reduces the chances of occurrence of resistant cases.

The study aims at analysing the histological patterns of Hansen's disease in skin biopsy specimens received in Histopathology Department in Medical College Kottayam and to correlate the histopathology and bacteriology in Hansen's disease.

\section{MATERIALS AND METHODS}

A descriptive study was conducted in 34 new clinically diagnosed cases of Hansen's disease received in the Department of Pathology in Govt. Medical College, Kottayam, during the study period of 18 months (May 2015 - November 2016).

\section{RESULTS}

Among 34 clinically diagnosed cases of leprosy, most common histological type was borderline tuberculoid followed by borderline lepromatous type. The maximum number of patients were in the age group of $31-40$ and $41-50$ yrs. Tuberculoid type and indeterminate type showed maximum clinicohistopathological correlation (100\%) followed by lepromatous leprosy (80\%). Midborderline cases showed minimum correlation. Cases in tuberculoid spectrum showed significant granuloma fraction, bacterial index and histopathological index. In our setting, modified Fite-Faraco stain is more superior than fluorescent staining for demonstration of bacilli in tissue sections.

\section{CONCLUSION}

Among 34 clinically diagnosed cases of leprosy, histological diagnosis of leprosy was established in $100 \%$ of cases. In our setting, modified Fite-Faraco stain is more superior than fluorescent staining for demonstration of bacilli in tissue sections. Tuberculoid type and indeterminate type showed maximum clinicohistopathological correlation $(100 \%)$ followed by lepromatous leprosy (80\%). Mid-borderline cases showed minimum correlation.

\section{KEYWORDS}

Hansen's Disease, Fluorescent Staining, Modified Fite-Faraco Stain.

HOW TO CITE THIS ARTICLE: Davis NT, Letha V, Sankar S. Histopathology and bacteriology in Hansen's disease. J. Evolution Med. Dent. Sci. 2017;6(91):6492-6496, DOI: 10.14260/jemds/2017/1410

\section{BACKGROUND}

Leprosy is a disease, which has been associated with tremendous social stigma with cases recorded in the old Testament. It is an infectious disease caused by Mycobacterium leprae. The organism grows in a cooler temperature than most bacteria and thus collects in cooler parts of the body such as the extremities and peripheral nerves. This disease presents with a variety of appearances based on the immune status of the patient. ${ }^{1}$

'Financial or Other Competing Interest': None.

Submission 12-10-2017, Peer Review 11-11-2017,

Acceptance 18-11-2017, Published 27-11-2017.

Corresponding Author:

Dr. Letha $V$,

Additional Professor

Department of Pathology,

Government Medical College,

Kottayam,

Kerala.

E-mail: drlethav@gmail.com

DOI: $10.14260 /$ jemds $/ 2017 / 1410$
The disease is endemic in many tropical and subtropical countries, but is declining in prevalence as a result of multidrug therapy. The most affected countries are India and Brazil with some countries in Sub-Saharan Africa and SouthEast Asia. ${ }^{2}$ In India it still remains a public health problem. There were 0.83 lakh leprosy cases as on April 1st 2011 with prevalence rate of 0.69 per 10,000 population. ${ }^{3}$ In most regions of the United States, leprosy is a rarity. However, an increased number of cases have been seen during the past decades as the result of the influx of immigrants from Asia and other regions of the world, in which the disease is still endemic. Therefore, the pathologist should consider it in the differential diagnosis of dermal granulomas and histiocytic tumours. ${ }^{4}$

The mode of transmission of leprosy is unknown, but it is probably inhalation of bacilli which may be excreted from the nasal passages of a multibacillary patient or possibly implanted from organisms in the soil. Direct person-toperson infection by means of the skin occurs rarely if at all. After inhalation, it is likely that bacilli pass through the blood 
to peripheral and cutaneous nerves, where infection and host reaction commence. 5

Leprosy expresses itself in different clinicopathological forms depending on the immune status of the patient. The immunopathologic spectrum is a dynamic continuum, in which patient moves in either direction according to host immune response and treatment. The standard delineation follows the classification of Ridley Jopling with categories defined along the spectrum by a combination of clinical, microbiological, histopathological and immunological indices. TT (Tuberculoid), BT (Borderline tuberculoid), BB (Midborderline), BL (Borderline lepromatous) and LL (Lepromatous leprosy). ${ }^{1}$

Diagnosis of leprosy only on clinical basis is difficult. So confirmation of diagnosis in leprosy is an important indication for histopathological examination. The parameters used for the histopathological classification are well defined, precise and also take into account the immunological manifestations which enable it to successfully bridge the pitfalls in leprosy diagnosis. Moreover, correct labelling of paucibacillary and multibacillary cases is a prerequisite to treat them adequately, which reduces the chances of occurrence of resistant cases. So not only histopathology, but also bacteriological diagnosis is very important in case of Hansen's disease. ${ }^{6}$

The TT and LL group of patients are stable and the latter remains heavily infected unless given chemotherapy. Tuberculoid leprosy (TT) shows a high cellular response characterised by $\mathrm{T}$ cell and macrophage activation and very few bacilli in tissues. Lepromatous leprosy (LL) on the opposite pole shows an absent cellular immunity to $\mathrm{M}$. leprae antigens with no macrophage activation and abundant bacilli in tissues. The central point of the spectrum BB is the most unstable with patients downgrading to LL if not treated.

Apart from these, there are some patients who are labelled as indeterminate leprosy and these are the patients with the earliest identifiable skin lesions that cannot be categorised definitely in the immunopathologic spectrum. Pure neuritic leprosy (PNL) is characterised by neural impairment without evidence or history of typical skin lesions. The diffuse type of leprosy called Lucio leprosy, which is most common in Mexico and also in Central America shows diffuse infiltration of the skin without nodules. This infiltration may be quite inconspicuous, except for the alopecia of the eyebrows and eyelashes it produces. Acral, symmetric anaesthesia is generally present. A distinctive variant of lepromatous leprosy, the histoid type, first described in 1963, is characterised by the occurrence of welldemarcated cutaneous and subcutaneous nodules resembling dermatofibromas. It frequently follows incomplete chemotherapy or acquired drug resistance, leading to bacterial relapse.

Patients were divided into two groups for therapeutic purposes: paucibacillary (TT, BT) and multibacillary (midborderline (BB), BL, LL). It was recommended later that the classification is to be based on the number of skin lesions, less than or equal to five for paucibacillary (PB) and greater than five for the multibacillary (MB) form.

Leprosy reactions are the acute episodes of clinical inflammation occurring during the chronic course of disease. They pose a challenging problem, because they increase morbidity due to nerve damage even after the completion of treatment. Leprosy reactions are classified into two main types (1 and 2). A third reaction is specific to Lucio multibacillary leprosy.

The study was conducted to analyse the histological patterns of Hansen's disease in skin biopsy specimens and to correlate the histopathology and bacteriology.

\section{MATERIALS AND METHODS \\ Methodology/ Type of Study \\ Descriptive study.}

\section{Study Period}

18 months (May 2015 - November 2016).

\section{Study Setting}

Department of Pathology in Govt. Medical College, Kottayam.

\section{Sample Size}

34 (All cases during the study period was included).

\section{Inclusion Criteria}

All new clinically diagnosed case of Hansen's disease sent for histopathological diagnosis are included.

\section{Exclusion Criteria}

Patients who already received antileprosy treatment are excluded. All relapse cases are excluded.

\section{Study Procedure}

34 cases of Hansen's disease received in the Dept. of Pathology during study period was included in the study.

\section{Histopathology}

An elliptical piece of skin is taken from the site of lesion by punch biopsy. The specimen is sent in $10 \%$ buffered formalin. It is then processed and paraffin embedding done. Serial sections are taken using a rotary microtome, which are then deparaffinized and stained with $\mathrm{H}$ and $\mathrm{E}$ stain. Histological examination is then done with the aid of light microscope.

\section{Modified Fite-Faraco Stain}

Deparaffinize sections in a mixture of xylene and peanut oil2 changes 6 minutes each. Drain, wipe off the excess oil and blot with filter paper. Wash in running tap water for 4 minutes. Stain with Ziehl-Neelsen's Carbol-Fuchsin solution for 30 minutes at room temperature. Wash in tap water for 2 minutes. Differentiate sections in 5\% H2SO4 in 25\% alcohol for two changes of 2 minutes each. Wash in running tap water for 5 minutes. Drain the excess water, bolt dry the sections. Clear in 2 changes of xylene and mount.

\section{Fluorescent Microscopy}

Place the slides $1 \mathrm{~cm}$ apart on staining rack. Flood slides with freshly filtered auramine- 0 and stand for 20 minutes. Rinse well with running water. Decolourise with acid alcohol for 3 minutes. Rinse well with water to wash acid alcohol. Counter stain with $0.5 \%$ potassium permanganate. Rinse with water and slope the slides to air dry. Reading is done under fluorescence microscope.

\section{Data Management and Analysis}

The data was entered in Microsoft Excel and further statistical analysis was done by using institutional software. 


\section{RESULTS}

After the analysis of 34 patients with Hansen's disease at Medical College Kottayam, the following observations were made. Among 34 clinically diagnosed cases of leprosy, most common histological type was borderline tuberculoid followed by borderline lepromatous type. The maximum number of patients were in the age group of $31-40$ and 41 50 yrs. The male: female ratio was 3.78. Nodular lesions were predominant in lepromatous spectrum and plaque lesions were common in tuberculoid spectrum. Majority of cases showed significant nerve involvement irrespective of the histologic types. Histopathology correlated with clinical diagnosis in $65 \%$ cases. Tuberculoid type and indeterminate type showed maximum clinic-histopathological correlation (100\%) followed by lepromatous leprosy (80\%). Midborderline showed minimum correlation. Majority of cases (70\%) showed epidermal changes in the form of thinning and erosion. Cases in tuberculoid spectrum showed significant granuloma fraction, bacterial index and histopathological index. In our setting, modified Fite-Faraco stain is more superior than fluorescent staining for demonstration of bacilli in tissue sections.

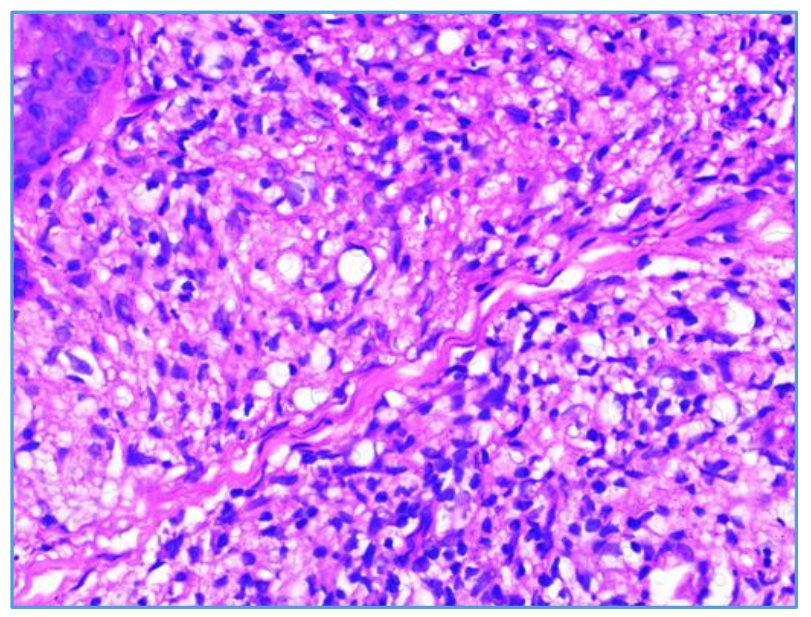

Figure 1. High Power View of Macrophages in Lepromatous Leprosy. H and E Stain 40x

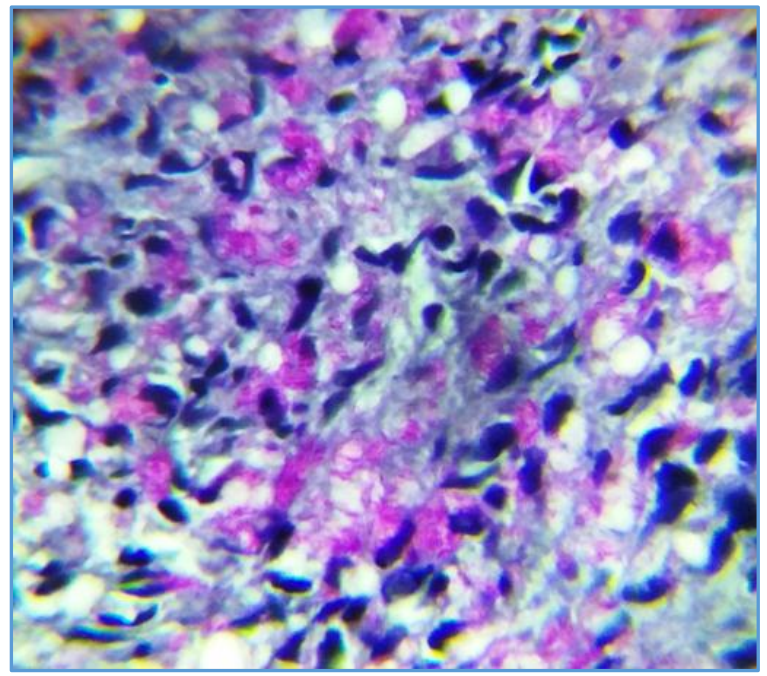

Figure 2. Bacterial Index of 6+ in Lepromatous Leprosy Modified Fite-Faraco Staining 100x

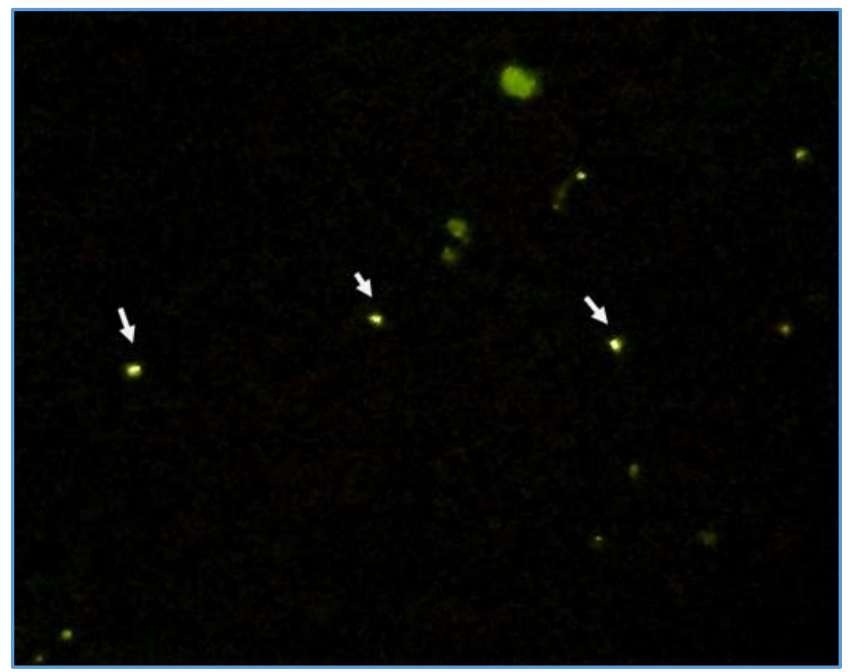

Figure 3. Fluorescent Staining showing a Bacterial Index of $2+$ in Lepromatous Leprosy $40 x$

\section{DISCUSSION}

The present study was conducted on 34 skin biopsy specimens of Hansen's disease received in the Department of Pathology, Government Medical College, Kottayam, between May 2015 and November 2016.

\section{Nature of Lesions}

According to the Study conducted by Manandhar et al, most common skin lesion in leprosy was plaque followed by macule. Macules were found to be the most common lesion in a study done by Vargas-Ocampo F et al. In the present study, majority of lesions were plaque (47\%). Nodular lesions predominate in lepromatous spectrum and plaque lesions were common in tuberculoid spectrum. This was found to be statistically significant.

\begin{tabular}{|c|c|}
\hline Manandhar et al & Plaque (40\%) \\
\hline Vargas-Ocampo F et al $^{7}$ & Macule $(37 \%)$ \\
\hline Present Study & Plaque (47\%) \\
\hline
\end{tabular}

\section{Nerve Involvement}

In the present study, majority of patients had nerve involvement (62\%) irrespective of histological type. Similar result was obtained by study conducted by Veena Shivamurthy et al (73.5\% nerve involvement).

\section{Clinical Diagnosis}

In our study, out of 34 patients, majority of patients (64\%) were clinically diagnosed as borderline tuberculoid type followed by lepromatous type (15\%). Of the remaining cases, borderline lepromatous constituted 4 cases (12\%). Tuberculoid type, mid-borderline and indeterminate type constituted 1 case each (3\%).

\section{Histopathological Diagnosis}

Among the 34 clinically diagnosed cases of leprosy, histological diagnosis of leprosy was established in $100 \%$ of cases. Borderline tuberculoid was the most common type of leprosy (38\%) followed by borderline lepromatous type (20\%). Least common types were indeterminate and midborderline type (3\% each). Comparable results were obtained by studies conducted by Giridhar and Veenashivamurthy et al. 


\begin{tabular}{|c|c|c|c|}
\hline Type & $\begin{array}{c}\text { Giridhar } \\
\text { et al }\end{array}$ & $\begin{array}{c}\text { Veenashivamurthy } \\
\text { et al8 }\end{array}$ & $\begin{array}{c}\text { Present } \\
\text { Study }\end{array}$ \\
\hline TT & $18 \%$ & $1.5 \%$ & $18 \%$ \\
\hline BT & $44 \%$ & $72.5 \%$ & $38 \%$ \\
\hline BB & $2 \%$ & $2.5 \%$ & $3 \%$ \\
\hline BL & $14 \%$ & $10.5 \%$ & $20 \%$ \\
\hline LL & $17 \%$ & $5.5 \%$ & $18 \%$ \\
\hline IND & $5 \%$ & $7.5 \%$ & $3 \%$ \\
\hline
\end{tabular}

\begin{tabular}{|c|c|c|c|c|c|c|c|}
\hline \multicolumn{7}{|c|}{ Veenashivamurthy et al } \\
\hline \multirow{2}{*}{ Type } & \multicolumn{7}{|c|}{ Bacterial Index } \\
\cline { 2 - 9 } & $\mathbf{0}$ & $\mathbf{1 +}$ & $\mathbf{2 +}$ & $\mathbf{3 +}$ & $\mathbf{4 +}$ & $\mathbf{5 +}$ & $\mathbf{6 +}$ \\
\hline TT & $100 \%$ & - & - & - & - & - & - \\
\hline BT & $94 \%$ & $8 \%$ & - & $1 \%$ & - & - & - \\
\hline BB & - & $40 \%$ & $60 \%$ & - & - & - & - \\
\hline BL & - & - & $19 \%$ & $52 \%$ & $14 \%$ & $14 \%$ & - \\
\hline LL & - & - & - & - & $27 \%$ & $54 \%$ & $18 \%$ \\
\hline IND & $100 \%$ & - & - & - & - & - & - \\
\hline
\end{tabular}

\section{Clinico-Histopathological Correlation}

Clinical and histopathological correlation was seen in 22 cases $(65 \%)$. The correlation was highest in tuberculoid type and indeterminate type (100\%) followed by lepromatous leprosy. Study conducted by Sehgal VN et al and Moorthy BN et al, the clinicohistopathological correlation was 33\% and $62.63 \%$ respectively.

\begin{tabular}{|c|c|}
\hline Study & $\begin{array}{c}\text { Clinicopathological } \\
\text { Correlation }\end{array}$ \\
\hline Sehgal VN et al ${ }^{9}$ & $33 \%$ \\
\hline Moorthy BN et al & $62.63 \%$ \\
\hline Present Study & $65 \%$ \\
\hline
\end{tabular}

According to study conducted by Manandhar et al, the maximum histopathological correlation was seen in borderline tuberculoid (63\%) followed by borderline lepromatous and lepromatous leprosy ( $57 \%$ each).

\begin{tabular}{|c|c|c|c|c|}
\hline $\begin{array}{c}\text { Type of } \\
\text { Leprosy }\end{array}$ & $\begin{array}{c}\text { Jerath VP } \\
\text { et al10 }\end{array}$ & $\begin{array}{c}\text { Nadkarni } \\
\text { NS et al11 }\end{array}$ & $\begin{array}{c}\text { Manandhar } \\
\text { et al }\end{array}$ & $\begin{array}{c}\text { Present } \\
\text { Study }\end{array}$ \\
\hline TT & $74.5 \%$ & $97 \%$ & $24 \%$ & $100 \%$ \\
\hline BT & $64.7 \%$ & $95 \%$ & $63.15 \%$ & $60 \%$ \\
\hline BB & $53.8 \%$ & $89 \%$ & $0 \%$ & $0 \%$ \\
\hline BL & $28.5 \%$ & $87 \%$ & $57.14 \%$ & $75 \%$ \\
\hline LL & $61.5 \%$ & $98 \%$ & $57.14 \%$ & $80 \%$ \\
\hline IND & $88.8 \%$ & & $0 \%$ & $100 \%$ \\
\hline
\end{tabular}

\section{Grenz Zone}

All lepromatous leprosy cases and $40 \%$ borderline lepromatous cases showed grenz zone in histopathology sections, but it was absent in mid-borderline and tuberculoid spectrum. Veenashivamurthy et al reported that $100 \%$ of lepromatous leprosy and $85 \%$ borderline lepromatous leprosy showed grenz zone.

\section{Granuloma Fraction}

Present study showed significant granuloma fraction in tuberculoid spectrum. All cases of tuberculoid type showed granuloma fraction above $0.7 \%$. In lepromatous spectrum, granuloma fraction showed low values. The association of granuloma fraction and histological types was found to be statistically significant ( $\mathrm{p}$ value $=0.001)$.

\section{Bacterial Index}

All cases of tuberculoid leprosy (100\%) showed a bacterial index of 0 . Majority of borderline tuberculoid leprosy cases (60\%) also showed bacterial index of $0.85 \%$ and lepromatous leprosy showed a bacterial index of 6 . Similar results were obtained by studies conducted by Veenashivamurthy et al.

\begin{tabular}{|c|c|c|c|c|c|c|c|}
\hline \multicolumn{7}{|c|}{ Present Study } \\
\hline \multirow{2}{*}{ Type } & \multicolumn{7}{|c|}{ Bacterial Index } \\
\cline { 2 - 9 } & $\mathbf{0}$ & $\mathbf{1 +}$ & $\mathbf{2 +}$ & $\mathbf{3 +}$ & $\mathbf{4 +}$ & $\mathbf{5 +}$ & $\mathbf{6 +}$ \\
\hline TT & $100 \%$ & - & - & - & - & - & - \\
\hline BT & $69.8 \%$ & $18.6 \%$ & $11.6 \%$ & - & - & - & - \\
\hline BB & & & & & & & \\
\hline BL & - & - & - & $25 \%$ & $62.5 \%$ & $12.5 \%$ & - \\
\hline LL & - & - & - & - & - & $25 \%$ & $75 \%$ \\
\hline IND & $100 \%$ & & - & - & - & - & - \\
\hline
\end{tabular}

\section{Histopathological Index}

Maximum histopathological index was seen in lepromatous leprosy in the range of $8-25$ lakhs bacilli per cubic $\mathrm{mm}$ of tissue followed by borderline lepromatous type. In BT and TT, maximum number of casas showed an HPI of $0-80$ bacilli/cumm. This was found to be statistically significant with a chi-square value of 49.39 and a p-value of 0.03 .

\section{Comparison of Bacterial Index in Modified Fite-Faraco and Fluorescent Staining}

Out of 34 cases, we did Fite-Faraco staining in all cases and fluorescent staining in 30 cases. The results obtained showed that modified Fite-Faraco staining is more sensitive than fluorescent stain for lepra bacilli. Majority of lepromatous leprosy showed a bacterial index of $6+$ in modified FiteFaraco staining, but with fluorescent staining only a maximum score of $2+$.

Lacordaire ${ }^{12}$ observed that modified Fite-Faraco method to be superior compared with fluorescent staining method. Presence of artefacts from albumin and phenol was found to be a major problem. According to study conducted by Nayak et $\mathrm{al}^{13}$ and Nagarajappa et al, fluorescent staining was more superior than modified Fite-Faraco staining, especially in paucibacillary cases.

\section{CONCLUSION}

Among the 34 clinically diagnosed cases of leprosy, histological diagnosis of leprosy was established in $100 \%$ of cases. Borderline tuberculoid was the most common followed by borderline lepromatous type (20\%).

In our setting, modified Fite-Faraco stain is more superior than fluorescent staining for demonstration of bacilli in tissue sections. In present study, out of 34 cases of leprosy, 17 were positive by the modified Fite-Faraco method and 8 cases by fluorescent microscopy.

Clinical and histopathological correlation was seen in 22 cases. The correlation was highest in tuberculoid type and indeterminate type.

As there can be some degree of overlapping among different types of leprosy both clinically and histopathologically, correlation of clinical and histopathological features along with bacteriological index appears more useful for accurate typing of leprosy than 
considering any of single parameters alone. This helps the clinician for better care and management of patients.

\section{REFERENCES}

[1] Definition, Epidemiology and world distribution. In: Jopling WH, McDougall AC. (eds). Handbook of Leprosy. $5^{\text {th }}$ edn. CBS Publishers 1996;1.

[2] Noordeen SK. Eliminating of leprosy as a public health problem: progress and prospects. Bull World Health Organ 1995;73(1):1-6.

[3] NLEP. Progress report for the year 2010-11 ending on 31st March 2011. Central leprosy division, Directorate general of health services, Government of India, New Delhi, 2011.

[4] Triscott JA, Nappi O, Gerrara G, et al. Pseudoneoplastic leprosy. Leprosy revisited. Am J Dermatopathol 1995;17(3):297-302.

[5] Lucas SB. Mycobacteria and the tissues of man. In: Ratledge C, Stanford J, (eds). The biology of the mycobacteria. Vol 3. London: Academic Press, 1988:107.

[6] Lucas S. Bacterial Disease. Lever's histopathology of skin. 10 ${ }^{\text {th }}$ edn. Lippincott Raven publishers, 2009:55867.
[7] Vargas-Ocampo F. Diffuse leprosy of Lucio and Latapí: a histologic study. Lepr Rev 2007;78(3):248-60.

[8] Shivamurthy V, Gurubasavaraj H, Shashikala PS, et al. Histomorphological study of leprosy. AfrJ Med Health Sci 2013;12(2):68-73.

[9] Sehgal VN, Rege VL, Reys M. Correlation between clinical and histopathologic classification in leprosy. Int J Lepr and Other Mycobact Dis 1977;45(3):278-80.

[10] Jerath VP, Desai SR. Diversities in clinical and histopathological classification of leprosy. Lepr India 1982;54(1):130-4.

[11] Nadkarni NS, Rege VL. Significance of histopathological classification in leprosy. Indian J Lepr 1999;71(3):32532.

[12] deFaria LL. Fluorescent staining of mycobacterium leprae in tissue sections comparison with Fite-Faraco internal procedure. Internal Journal of Leprosy 1974:42(1):52-4.

[13] Nayak SV, Shivarudrappa AS, Mukkamil AS. Role of fluorescent microscopy in detecting mycobacterium leprae in tissue sections. Ann Diagn Pathol 2003;7(2):78-81. 